\title{
ESTUDIOS JUDAICOS EN LA UNIVERSIDAD DE CHILE: ENSEÑANZA DEL JUDAÍSMO A NO JUDÍOS (Una experiencia personal)
}

Entre las tareas académicas que desarrolla el Centro de Estudios Judaicos de la Universidad de Chile está la docencia de prestación de servicios a alumnos de la Facultad de Filosofía y Humanidades a la que pertenece. Los cursos son electivos y otorgan créditos reconocidos en las respectivas carreras. El listado de cursos ofrecidos ha sido siempre variado pero, curiosamente, nunca se había dictado un curso específico sobre "Judaísmo".

Decidida a "reparar" esta omisión, en 1987 decidí dictar un curso titulado "Judaísmo, ¿religión o cultura?". El contenido del mismo incluía historia, religión, costumbres y tradiciones.

Fue una experiencia enriquecedora: Los alumnos tuvieron la oportunidad de adentrarse en un mundo que siempre les había resultado ajeno y extraño. En lo personal, aprendí mucho de quienes se inscribieron en la asignatura.

Resultó interesante conocer la motivación que los había llevado a tomar este curso y no otro de los electivos que se les ofrecieron.

Todos, en mayor o menor medida, tenían ideas pre-concebidas sobre los judíos. Su "conocimiento" acerca del judaísmo y los judíos provenía de las diversas opiniones que habían escuchado: Sabían que ya el sólo término "judío" provocaba encontradas opiniones y evitaban mencionarlo.

Reconocían tener "prejuicios" y esperaban que el curso les permitiera conocer algo acerca de esos enigmáticos seres y su cultura tan celosamente custodiada. De este modo, a través del conocimiento, ellos podrían reafirmar sus prejuicios o simplemente eliminarlos.

La actitud de estos jóvenes revelaba el grado de madurez que poseían, su deseo de comprender y conocer situaciones, su capacidad de raciocinio y constante búsqueda de fundamentos para actuar de modo consecuente.

$Y$ así fue como quienes llegaron en un comienzo predispuestos a no ser convencidos de nada que no estuviese de acuerdo con sus principios, fueron mostrándose receptivos y abiertos a un intercambio de opiniones honestas y francas que permitió la creación de un espacio de encuentro que no concluyó con el semestre, ya que la relación entre nosotros se mantiene hasta hoy día.

Los prejuicios y los malos entendidos fueron disipándose en la medida en que las situaciones fueron insertas dentro del contexto histórico-social correspondiente.

Imposible transcribir en unas pocas páginas lo tratado durante un semestre. 
¿Qué opinión tenían de los judíos? ¿Cuánto conocían acerca de este grupo humano y cuál era la fuente de este conocimiento? ¿Qué contactos habían tenido con judíos? ¿Cuáles eran los defectos más visibles y recurrentes en los judíos?

Podemos resumir diciendo que, los judíos aparecían como individuos poco confiables, - un grupo cerrado, - ambiciosos, avaros, - extremadamente racionalistas, - orgullosos de ser diferentes al resto, se consideran superiores, pueblo elegido, - no se mezclan con nadie sólo entre ellos, - machistas que relegan a un plano inferior a las mujeres. Y lo que resultaba bastante grave: no aceptan a Jesús como Cristo y mucho menos como Dios hecho hombre.

Si bien el descrito no es un perfil halagüeño para los judíos, para los alumnos resultaba muy real, porque.... ¿cuál es era el conocimiento que tenían sobre los judíos y de donde procedía?

Algunos tenían referencia por las narraciones bíblicas. El Antiguo Testamento les declara pueblo elegido de Dios, pueblo de dura cerviz y rebelde. El Nuevo Testamento les señala que Jesús y su familia eran judíos y, sin embargo, los judíos no solo no creyeron en él sino que además fueron responsables de su muerte.

Otros habían tenido acceso a información a través de la literatura y el cine, donde no siempre hay una evaluación positiva de los judíos (baste recordar, entre otras, las obras de Shakespeare, Marlowe, Scott y Gonzalo de Berceo).

Otros habían leído obras que trataban hechos históricos recientes y muy concretos, temas que no siempre se encuentran presente en los programas de Historia Contemporánea, como los narrados en las novelas Éxodo y Holocausto (Historia de la Familia Weiss) y series de televisión homónimas.

Lo interesante era indagar por qué creían ellos que la imagen del judío resultaba tan negativa. Entre los factores que mencionaron, aparecieron:

a) La falta de conocimiento y que la desinformación existente era, además, la principal causa del anti-judaísmo porque aunque los ghettos ya no existían, la cultura judía seguía siendo hermética e inaccesible para la mayoría no judía. Esta imagen -dijeron- cambiaria mucho si ella -la culturafuera más abierta".

b) Que aparecían poco confiables ya que siempre tenían argumentos (que ellos consideraban válidos) para aquello que sustentaban y siempre se mostraban demasiado seguros de sus afirmaciones.

c) Que en materia de religión eran excesivamente racionales y este racionalismo era visto como un recurso por medio del cual los judíos trataban de justificar su manera de ser y el saberse elegidos les hacía diferentes y sagrados, excluyendo al resto del mundo de la posibilidad de serlo. Es más, el saberse elegidos les hacía sentirse superiores al resto de los pueblos con los que, obviamente, no se mezclaban.

Resultaba notoria la connotación que daban al concepto de "pueblo elegido". Era imprescindible clarificar dicho concepto, ya que la elección como pueblo fue más bien una concesión graciosa que Dios les habría hecho no por ser mejores que el resto de los pueblos, sino por haber aceptado Su Alianza.

Debía quedarles claro que dicha elección implicaba el cumplimiento de una normativa de vida que si era quebrantada se castigaba severamente: Israel debía ser 'or ha goyim' ("luz de los pueblos"), un ejemplo del modo como había que cumplir el pacto y su misión era la de dar a conocer la existencia de un Dios único y universal.

Respecto a la afirmación de que los judíos todos eran avaros, fríos y calculadores, un integrante del curso señaló que, después de conocer las vicisitudes históricas, esta actitud podría comprenderse como el fruto de las grandes dificultades que habían tenido que sufrir para conseguir lo que poseían y por eso defienden y cuidan sus bienes excesivamente. Podía también, evidenciarse que la mayoría de los judíos poseían una capacidad para administrar sus pertenencias y que su avaricia no era tal en la medida en que comparten, se ayudan y son muy solidarios entre ellos. 
Un rasgo importante de esta imagen poco grata de los judíos, era el rechazo a los no judíos manifestado en la frase los judíos sólo se casan entre judíos y rechazan todo tipo de matrimonio mixto.

En este punto, y porque el grupo de alumnos se caracterizaba por su heterogeneidad religiosa, decidí hacer una prueba con ellos mismos para demostrarles que dicha actitud no era, en absoluto, privativa de los judíos. ¿Cómo? ¡Preguntando! Así es como pregunté a una joven católica si estaría dispuesta a casarse con un Testigo de Jehová; al Testigo de Jehová le pregunté si se casaría con una Adventista, y a un Adventista le pregunté si lo haría con una Bautista. La negativa brotó en forma espontánea.

Es muy significativa la respuesta de ustedes -les dije- la fe en Cristo es lo esencial que ustedes comparten y, sin embargo, a pesar de ser todos cristianos, cada uno quiere formar una pareja acorde a sus propios principios religiosos de grupo y no mezclarse con otro tipo de cristiano.

Lógico, -respondieron-, después de todo en los Evangelios está escrito: 'cada oveja con su pareja'.

De acuerdo, -respondí- pero si es lícito que un católico forme un hogar católico, un adventista un hogar adventista y un bautista quiera una familia bautista... ¿por qué negarles a los judíos, el mismo derecho? ¿Por qué acusarles de separatistas por querer algo que para ellos era tan normal y deseable? En verdad ¿son los judíos los que se creen diferentes o ustedes los que les consideran de ese modo?

El ejemplo resultó altamente esclarecedor y también muy desconcertante para ellos, al percatarse de su propia actitud.

Un tema que no podía soslayarse en modo alguno, era el relacionado con Jesús en tanto Cristo. Veamos algunas de las opiniones:

¿Los judíos?, jellos mataron aquello de lo que nosotros vivimos, lo que nos da la fuerza para existir!

Si ellos piensan que Cristo fue un hombre bueno, que alcanzó cierta perfección, y dividió la historia en dos, a.C. y d.C. ¿por qué los judíos no lo aceptaron y por qué están sometidos al calendario cristiano?

Cristo es la piedra angular de mi religión... es la prueba viviente de la existencia de Dios...

El tema de Jesús es la diferencia básica entre judaísmo y cristianismo, por lo que conversamos mucho sobre ese tema y uno de los trabajos finales versó, justamente, sobre él. Los siguientes son algunos comentarios extractados de ese escrito:

Cristo fue un judío, esta afirmación pocas veces se expresa, por no decir nunca... Hoy en los catecismos se inserta a Jesús en el pueblo judío más como un hecho anecdótico y circunstancial que para resaltar la verdadera importancia que este hecho adquiere hoy en día...

...Cristo fue un judío, es necesario volcar nuestras miradas a este aspecto y demostrar que judíos y cristianos tienen mucho más en común de lo que las autoridades respectivas estarían dispuestas a aceptar en relación al ideal de vida que ambas religiones propenden...

Al referirse a los judíos en tanto padres espirituales del Cristianismo, señalaba que sobre este aspecto hay consenso y se preguntaba, ¿si esto es un hecho acaso no es necesario propagarlo con más fuerza por el bien de ambos pueblos, por la convivencia más armoniosa entre practicantes de ambas religiones...?

La diferencia entre Cristianismo y Judaísmo radica en la figura de Cristo, sin embargo su enseñanza no contradice la enseñanza judía de un modo severo, en este sentido me inclino a pensar que el Dios de los 
cristianos y los judíos es el mismo, y esto principalmente es lo que me interesa que los creyentes asimilen, que la diferencia es formal y no de contenido...

En cuanto a la Iglesia como institución, todo parece indicar que su voz no se ha sentido con la fuerza suficiente como para hacer reaccionar al mundo, frente a hechos tan irreparables como el genocidio de la Segunda Guerra Mundial y otras situaciones parecidas a estas, como la que se vive con Sudáfrica, en donde ha tenido una tibia reacción...

El consenso es que la Iglesia puede y debe actuar enérgicamente en relación a estos temas, arriesgarse hasta el fin, como lo hizo Cristo, pues se pretende su seguidora...

Existen hoy en día sacerdotes que afirman que los judíos tienen sólo la mitad de la verdad, yo no me siento llamada a otorgar grados de verdad a tal o cual religión, pero me parece una pedantería que miembros de la Iglesia Católica afirmen despectivamente cosas como éstas. Creo que se hace urgente hoy más que nunca un poco más de humildad para respetar los diferentes credos religiosos, para admirar a un pueblo que se ha mantenido unido a lo largo de su difícil historia por la fe en Dios, y son precisamente afirmaciones como la descrita las que esconden el germen del fanatismo y de la intolerancia de lo cual, son los judíos los mejores exponentes de sus fatales consecuencias.

A lo ya expresado agreguemos otras opiniones:

No sé ni es mi intención juzgar cuál de las dos religiones está más cerca de Dios, eso le corresponde a El. Sólo quiero expresar que una de las cosas que más me ha llamado la atención y ciertamente me ha desconcertado, es el saber más acerca de la religión judía, me parece comprender su problemática, pero sentirme más lejos de ella que de la evangélica, tanto es así que me parece que adoramos a dos dioses diferentes. Antes yo me sentía más identificada con ella por el hecho de creer en un Dios que fue hombre y hombre judío, que vivió y murió según las tradiciones de su pueblo...

Como católica lo más importante para mí y en definitiva lo que me impulsó a seguir este curso fue el deseo de saber por qué los judíos niegan a Jesús como Dios hecho hombre, creo que después de haber aprendido muchas cosas que ignoraba, aún no encontré ninguna razón válida para mí, quizás mi profunda fe en el hijo de Dios me impida ver con claridad los motivos de los judíos, pero es algo inevitable, inherente a mí, es algo tan arraigado que no me puedo desprender ni por un minuto, aunque siento que estoy más abierta a escuchar que antes...

Una pregunta importante, destinada a hacerles reflexionar, fue motivo de desconcierto. No me cabe duda alguna que les habría resultado mucho más fácil escribir un trabajo sobre una época histórica o sobre algún tema que no les comprometiera en lo personal. Pero dar respuesta a la pregunta "¿En qué medida el conocer sobre Judaísmo le ha servido para comprender su propio pensamiento religioso?" significaba un cuestionamiento interno acerca de su propia religiosidad e interiorizarse y conocer más acerca de su propio Credo.

No todos se sintieron capaces de aceptar este desafío a sí mismos y a su propia verdad. Pero quienes lo hicieron asumieron honestamente su labor y me congratulo en saber que la introspección les ayudó a crecer y madurar su pensamiento y su posición frente a sí mismos y a su religiosidad.

Los párrafos que transcribo a continuación, forman parte de las reflexiones de los alumnos, emitidas ya sea al iniciar su escrito -a guisa de introducción- o bien al término, a modo de conclusión: 
El trabajo... me pareció al principio muy difícil, luego no tanto, pero al empezar a hacerlo me di cuenta de que quien lo había escrito era una joven de 20 años, que no había llegado aún al entendimiento y a la total aceptación de su propia religión, por esto me pareció importante, antes de emitir mis juicios, saber qué piensan quienes se definen como católicos maduros y comprometidos. $Y$ así me dediqué a hablar con sacerdotes, religiosas y laicos comprometidos en general...

Después de narrar parte de su experiencia, ella señala que surgieron muchas interrogantes, pero que su objetivo era graficar las diferencias y similitudes que tienen estas dos religiones, esto con las limitantes que me pone el conocimiento imperfecto de mi religión y más aún de la judía... Todo esto de la forma más objetiva posible, aunque pienso que, en política y religión, el concepto de objetividad absoluta no existe...

Y esta alumna concluye señalando que la experiencia de seguir este curso me ha sido provechosa no tan sólo por el hecho de conocer otra religión sino también porque me permitió madurar y reflexionar como católica sobre mi propia religión, pues me he tenido que interiorizar más de ella para emitir juicios fidedignos.

Otra alumna escribe:

Mi religión es el Cristianismo y creo que entre éste y el Judaísmo hay similitudes, como ser el hecho de que parten de una misma raíz, en nuestra Biblia tenemos los libros de Génesis o libro de los comienzos, la creación del mundo y del hombre, se muestra la gracia de Dios al hacer al hombre a su imagen, así también con el diluvio y la historia del pueblo a quien Dios eligió como suyo, el pueblo de Israel. De este pueblo habría de nacer Jesús, el inspirador del Cristianismo y aquí es donde radica la diferencia con el judaísmo.... para los cristianos Jesús es el Mesías prometido...

En su nota final se refiere a la admiración que siente por Israel, el pueblo elegido por Dios, rememora las historias que su abuela le contaba acerca de héroes bíblicos y destaca el hecho de que, a pesar de su dispersión, pese a todo, mantiene ligado a sus integrantes en comunidades ya sea por unión de tipo nacional o religioso.

Concluye diciendo: El trabajo realizado fue de mucha ayuda... pues me llevó a meditar acerca de mí misma y de lo que pienso, a tener una idea más o menos clara y precisa de mi fe, al darme cuenta que en ella se encierran sentimientos más íntimos: victorias, derrotas, alegrías y tristezas en la relación del hombre con Dios.

Una tercera reflexión nos dice:

Creo en las cosas fundamentales y estoy de acuerdo con el judaísmo porque para mí, al igual que para los judíos, lo importante es hacer de este mundo un mundo mejor, y para ello lo importante son las acciones, y dentro de estas acciones la labor del Centro de Estudios es muy apropiada...La única conclusión a la que puedo llegar es que aún hoy existen muchísimos prejuicios hacia los judíos, que no hay una actitud honesta y profunda para acercar a judíos y cristianos, que en los sectores más populares del catolicismo hay fanatismo y erradas interpretaciones, que hay mucha soberbia de parte de los católicos en relación a las demás religiones....

Mientras esto exista no hay ninguna seguridad de que nuevas catástrofes como las ya vividas no se repitan y que situaciones de injusticia sucedan ante los ojos del mundo sin que una colectividad lo 
suficientemente numerosa se pronuncie, actúe con energía y determinación y que asistiremos impávidos al espectáculo de nuestra propia destrucción...

A la conclusión anterior, que refleja un tono desesperanzado que ansía ver cambios en la actitud humana en general y de su iglesia en particular, podemos sumar la reflexión de quien dice no tener religión alguna y estar en un momento de búsqueda e indagación:

En todo caso, -dice-, creo en Dios al igual que los judíos pues pienso que debe existir una causa primera, un ente, un ser que de una u otra forma organiza y rige a todo el universo, pero lo visualizo quizás como una entidad menos personificada. Tal vez Dios existe porque necesitamos que exista... tal vez creo en Dios porque Dios me es necesario como aliciente y como respuesta a tantas inevitables interrogantes existenciales... Veo también que es importante el hecho de que las religiones, en este caso la judía no sólo se proyecten hacia lo que se relaciona a lo ceremonial, litúrgico, etc. sino por el contrario, se oriente hacia lo cotidiano, lo que la vida en sociedad significa: lo que es ser entre y con todos. El conocer sobre judaísmo, si es que puedo aclarar que conozco algo acerca de él (cosa que prefiero no hacer) me ha servido, pues creo que no podemos permanecer indiferentes ante esta religión que de una u otra forma toca nuestros pensamientos...

La historia milenaria, la tradición y la transmisión de valores a través del tiempo y la unión que persiste en el judaísmo es un elemento que estaba presente... a pesar de "tantas duras experiencias".

¿Es que los judíos llevan en sí una especie de estigma que siempre les ha causado dolores y sufrimientos, que les ha convertido en el blanco de odios, persecuciones, maltratos y cruel exterminio, muchas veces de parte de o bajo la complicidad de quienes dicen obedecer una fe justa?

¿Qué hay en la historia de este pueblo? La respuesta a esta interrogante, a la vez que permite a la alumna intentar comprender cosas que parecen a simple vista inexplicables, le plantea problemas ante su propia fe:

Tantas duras experiencias, tantos sufrimientos me ha hecho preguntarme muchas veces si esto no será una especie de prueba que se les ha impuesto para probar que son una nación fuerte que, por dura que sea la prueba, sale cada vez más fortalecida. En esta situación de enfrentar y vencer a la adversidad influye tal vez un hecho fundamental y es la unidad de este pueblo. Una unidad que se ha mantenido desde siempre a pesar de existir diferentes corrientes de pensamiento en su gente. Esta unidad se manifiesta en torno, pienso, a su rica tradición y a su fe, aspecto que considero muy importante ya que a través de él puedo hacer una crítica a mi propia fe, o mejor dicho, a su organización...

Ella escribe que, en lo personal, no practica ninguna religión en particular, pero que se considera cristiana y a través de su intuición intenta regirse por principios, "por valores que considera fundamentales".

Su credo contempla el hecho de que cada ser humano es diferente y único y tiene sus propias razones muy valederas-, para pensar y actuar acorde a ellas, cree en la libertad como derecho fundamental de todo ser viviente y acepta como valedera toda creencia o fe que impulse al ser humano a ser cada vez mejor, a tratar de comprender y superarse.

Explica por qué decidió no ser partícipe de ninguna religión o iglesia en particular y, entre otras razones, aduce el hecho de que existe una gran diversidad cuyo único interés aprecia como "partidista", lo que contribuye única y exclusivamente a separar aún más a las personas, ya que cada una está interesada en demostrar que su propia organización es la mejor y que, por supuesto, es la única que adora a Dios de la mejor manera, lo que ha comprobado personalmente.

Se evidencia en su pensamiento un deseo de unidad, un sentir que todos los cristianos deberían actuar como Jesús en vez de luchar por hacer una organización poderosa. El suyo es un grito pidiendo que se llegue al hombre común, al hombre simple, entregándole el mensaje adecuado, un mensaje de unidad. 
Concluye señalando que hay muchas dudas respecto a la fe judaica que me habría gustado aclarar en el curso de Judaísmo, pero por la irregularidad del semestre, no se pudo. Sin embargo, -dice-, pude comprobar que el pueblo judío es especial, muy especial. El doble esfuerzo que han debido realizar siempre por obtener lo justo, lo normal, los ha hecho crecer y amar por sobre todo su condición de judíos. Esto, por lo menos para mí -señala-, constituye un gran ejemplo, un ejemplo digno de ser imitado.

Ha pasado el tiempo y en conversaciones posteriores, hemos concluido que el espacio que se dio en el interior del curso fue valioso. Por primera vez se vieron enfrentados a algo que les atañía muy en lo personal: sus sentimientos religiosos. A lo largo de las carreras que estudian pueden discutir 'objetivamente', 'científicamente'; el tópico es el objeto y ellos, el sujeto que inquiere acerca de ese objeto que está más allá de ellos mismos.

En este curso, en cambio, objeto y sujeto se fundían. No había cientificidad posible. Por mucho que se la buscara, debían asumir cada uno su rol de creyente o no creyente, observante o no observante; debían cuestionarse, debían interrogarse a sí mismos e interrogar a otros acerca de aquello que les era tan propio y que, a veces, les parecía no conocer a fondo.

No era un juicio donde había perdedores y ganadores. Todos ganamos al estar cara a cara conversando como amigos. Abriendo nuestras mentes, intentando comprender, dialogando. No se trataba en modo alguno de convencer o de luchar para no ser convencido: nuestros pensamientos íntimos salían a flote, nuestros prejuicios fluían sin vergüenza: "Esto es lo que pensamos, ¿que puede usted decir al respecto?". Hubo respuestas situadas en el tiempo y en el espacio, había que contextualizar situaciones porque era el único modo de comprender ciertas actitudes y acciones. Hubo diálogo. Los muros del ghetto en verdad cayeron ante ellos y vieron que en el judaísmo no había nada que ocultar y mucho por mostrar, mucho para compartir en una actitud abierta y franca que hacía honor a la regla de oro "Ama a tu prójimo como a ti mismo". Y, para un judío, un no judío es también su prójimo.

No quise concluir este escrito sin antes conversar sobre su contenido con algunos de mis alumnos y la reflexión de uno de ellos me dejó pensativa:

¿Sabe, profesora? Creo que quedamos con un sentimiento de nostalgia. Los judíos tienen clara su historia y su tradición y la asumen como parte de su forma de vida. En su presente, constantemente se evidencia su pasado y se tiene clara una perspectiva futura... El judaísmo es mucho más que una religión, es una cultura vasta y rica que dan deseos de conocer más en profundidad. Me pregunto ¿sabemos nosotros nuestro origen? ¿Tenemos claro los fundamentos de nuestra religiosidad? ¿Conformamos nosotros una cultura y si es así, cuáles son sus elementos, cómo caracterizarla, cómo vivirla plenamente?

Recordando el curso, que ya ha sido impartido en diversas oportunidades, no puedo sino sonreír con satisfacción. No quisiera que se malinterprete: no es vanidad ni mucho menos orgullo. Es la satisfacción de saber que estamos sembrando una semilla que la comprensión, la apertura de mente y el no dogmatismo ayudará a germinar. La certeza de que en estas oportunidades de encuentro y aprendizaje mutuo hemos sido capaces de crear lazos a pesar de nuestras diferencias, de hablar y saber escuchar, de conocernos y respetarnos, de crecer en este diálogo directo que nos permitió vislumbrar un futuro en el que los prejuicios cederán paso a la comprensión y, con ello, colaborar en una tarea que debe ser de todos: intentar hacer de éste, un mundo mejor... 
Recibido el 28 Abr 2008

Aceptado el 10 Dic 2008 